Research Article

\title{
POLYMORPHISM OF SAKINI CHICKEN POPULATION FROM DIFFERENT LOCATIONS/ALTITUDES OF NEPAL USING RANDOMLY AMPLIFIED POLYMORPHIC DNA MARKERS
}

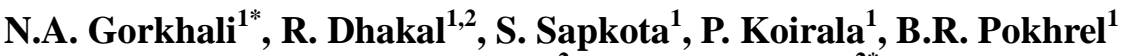 \\ M.R. Kolachhapati ${ }^{2}$ and N. Bhattarai ${ }^{2 *}$ \\ ${ }^{1}$ NationalAnimal Breeding and Genetics Research Centre \\ Nepal Agricultural Research Council, Kathmandu, Nepal \\ ${ }^{2}$ Agriculture and Forestry University, Chitwan, Nepal
}

\begin{abstract}
A study was conducted to evaluate genetic polymorphism in three Sakini chicken populations using random amplification of polymorphic DNA (RAPD) with seven highly polymorphic primers. All populations showed polymorphism with these primers that generates 59 different bands with an average of 8.4 bands per primer with $78.6 \%$ polymorphism nature. Primer OPA-16 produced the highest number of polymorphism bands $47 \%$ and the lowest number of bands was produced by the OPA-05 primer $24 \%$. Differences for genetic distance (D) among populations were significant $(\mathrm{P}<0.05)$. A consensus dendogram was therefore developed to show the phylogenetic relationship among the populations. The cluster pattern is well supported by the principle component analysis that also separates all three populations of Sakini chicken into six major groups. The results provide evidence of the applicability of RAPD to determining genetic relatedness within and among different poultry populations and in developing reproducible markers useful in evaluating individual variation in poultry.
\end{abstract}

Keywords: Sakini chicken, Genetic polymorphism, Polymorphic DNA

\section{INTRODUCTION}

Sakini, a principal and most common chicken breed in Nepal distributed throughout the country. They are dual purpose breeds having a small body size with colorful plumage and well-known for unique quality of meat and eggs. Indigenous poultry including the Sakini breed contributes almost $55 \%$ of the total poultry population in

*Corresponding author: nbhattarai@afu.edu.np 
Nepal (Ministry of Livestock Development, 2015). Overall productivity of this breed is low in farmer's households, may be because of farmer's poor knowledge on breeding, health and nutrition management (Wilson, 2017); thus, it could be increased through genetic improvement by using the process of selection (Sapkota et al., 2017). Since selection is a time taking process, the Department of Livestock Services of Nepal Government has taken the crossbreeding strategy for the immediate benefit of the poor farmers by introducing exotic breeds (Neopane and Gorkhali, 2008). This unplanned crossbreeding with indigenous chicken created a threatening situation with genetic dilution. The need to curb the threats of dilution and extinction of the Nepalese chicken genetic resources by strategic development and conservation is justifiable and timely. The molecular characterization of indigenous chicken is the prerequisite for understanding about the breed then after developing efficient strategies for conservation. This present study was thus conducted to evaluate genetic polymorphism in three Sakini chicken populations using random amplification of polymorphic DNA (RAPD) with seven highly polymorphic primers.

RAPD technique has made a substantial contribution as a simple technique, which is affordable to a broad community working in molecular genetics with limited resources. RAPD markers are polymorphic DNA which is separated by the process of gel electrophoresis after polymerase chain reaction with the help of short random oligonucleotide primers (Welsh and McClelland, 1990; Williams et al., 1990). It is considered as one of the simple, safe, less expensive and rapid methods to figure out genetic diversity and similarity in various organisms which attributes to its use in molecular and genetic studies. This technique has been widely used to perform genome mapping in chickens (Levin et al., 1994; Cheng et al., 1995), genetic diversity and parentage analysis in chickens and turkeys (Smith et al., 1996). At present, RAPDs have been used for detecting specific markers to estimate genetic relatedness among various poultry species and to discriminate the genetic resources of economically important animals such as poultry (Salem et al., 2005). Thus, the ultimate intention of this project is to determine genetic variability among different Sakini chicken breeds and to confirm the genetic relationship among them with the use of RAPDs markers.

\section{MATERIAL AND METHODS}

\section{Sampling protocol, DNA extraction and analysis}

The sampling strategy for each breed avoided the selection of more than two birds from one household and served from the same cockerel. Blood was collected from the jugular vein and used to prepare DNA using a commercial DNA extraction kit (G-Dex DNA extraction kit). Samples were adjusted to a concentration of $20 \mathrm{ng} / \mu \mathrm{l}$ before PCR amplifications which were performed on single-bird DNA. Out of 162 birds that were taken for the phenotypic characterization of Sakini chicken of 
different agro-ecological zones of Nepal (Rasuwa for high hills, 61 birds; Kavre for mid-hills, 40 birds; and Rautahat for Terai, 61 birds), twenty samples from different districts were taken randomly and studied for molecular characterization.

\section{RAPD analysis}

The RAPD-PCR was performed on a Programmable Thermal Controller (Bio-Rad Laboratories Inc., USA). Each 10 $\mu 1$ reaction mix comprised: 20 ng template DNA, 6 pmol primer, dNTPs (de-ox nucleoside triphosphates) each at $50 \mu \mathrm{M}, 0.5$ units Taq DNA polymerase (Bioneer Corporation, South Korea) $10 \mathrm{mM}$ Tris $\mathrm{pH} 8.3,50 \mu \mathrm{M}$ KCI, $0.001 \%$ gelatin, $0.025 \%$ Tween-20, $0.25 \% \mathrm{NP} 40$ and $1.5 \mathrm{mM} \mathrm{MgCl}$. Temperature cycling comprised 40 cycles of $10 \mathrm{~s}$ at $95^{\circ} \mathrm{C}, 5 \mathrm{~s}$ at $35^{\circ} \mathrm{C}$ and $1 \mathrm{~min}$ at $72^{\circ} \mathrm{C}$. PCR products were subjected to electrophoresis at $150 \mathrm{~V}$ in $2 \%$ agarose gels containing ethidium bromide. RAPD fingerprints were visualized by ultraviolet (UV) illumination.

\section{Primers}

A total of seven arbitrary oligonucleotide primers were used singly for amplification of the breed-specific DNA pools (Table1). The primers, which discriminated between the DNA pools, were investigated further on single DNA samples to determine the proportion of animals carrying the pool-specific fingerprints. All the seven primers were $10 \mathrm{bp}$ long with a GC content of 45-80\%. Sequences for the primers that amplified apparent pool-specific products are shown in Table 1.

Table1. Name of primers with sequence and polymorphic information content (PIC)

\begin{tabular}{clcc}
\hline S.N. & Primers & Sequence 5'-3' & PIC \\
\hline 1 & OPA-04 & AATCGGGCTG & $0.37 \pm 0.07$ \\
2 & OPA-05 & AGGGGTCTTG & $0.24 \pm 0.22$ \\
3 & OPA-06 & GGTCCCTGAC & $0.34 \pm 0.14$ \\
4 & OPA-07 & GAAACGGGTG & $0.31 \pm 0.16$ \\
5 & OPA-11 & CAATCGCCGT & $0.34 \pm 0.19$ \\
6 & OPA-12 & TCGGCGATAG & $0.38 \pm 0.13$ \\
7 & OPA-16 & AGCCAGCGAA & $0.47 \pm 0.04$ \\
& Average & & $0.35 \pm 0.14$ \\
\hline
\end{tabular}

\section{Scoring of bands and statistical analysis}

Only distinct, prominent bands were scored, which represented RAPD fingerprints ranging from 0.31 to $1.1 \mathrm{~kb}$ in size. RAPD fingerprints were compared only on samples run in the same gel. Amplified DNA representing separate PCR products was scored and put in a data set for analysis of the following statistics.

Frequency of polymorphic fingerprints in the different breeds, determined from the ratio of the number of animals carrying the fingerprint (n) to the total number of animals screened within a breed $(\mathrm{N})$. 
Similarity index or allele (band) sharing (AS), calculated between breeds as follows: AS between animals $a$ and $b=(2 \mathrm{Bab}) /(\mathrm{Ba}+\mathrm{Bb})$, where $\mathrm{Bab}$ is the number of fingerprint bands shared by animals $\mathrm{a}$ and $\mathrm{b}, \mathrm{Ba}$ is the number of fingerprint bands in animal $\mathrm{a}$ and $\mathrm{Bb}$ is the number of fragment bands in animal $\mathrm{b}$ (Lynch, 1990).

Genetic distances between breeds.

Mean average percentage difference (MAPD). This value was calculated using the following three formulae (Gilbert et al., 1990):

1) Percentage difference $(\mathrm{PD})=\mathrm{Nab} / \mathrm{Na}+\mathrm{Nb} \times 100$

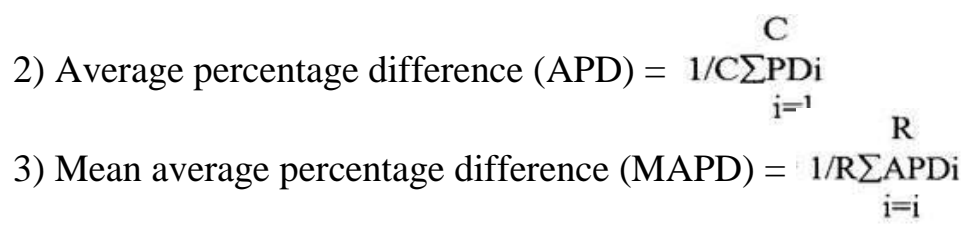

Where, Nab is the number of fragments that differed between two individuals for a single primer; $\mathrm{Na}$ is the number of fragments resolved in individual $\mathrm{a} ; \mathrm{Nb}$ is the number of fragments resolved in individual $b$; $C$ is the number of interbreeding pairwise comparisons, and $\mathrm{R}$ is the number of random primers used.

The MS Excel (version 5) and STATISTIX (version 4) analytical software were used to compute allele frequencies and mean values, respectively. The DISPAN computer program (1993) was used to calculate genetic distances and phylogenetic relationships between breeds.

\section{RESULTS AND DISCUSSION}

Sakini chicken of different lines showed polymorphism with seven RAPD primers consistent banding pattern (Table1) that generates 59 different bands with an average of 8.4 bands per primer with $78.6 \%$ polymorphism nature. Primer OPA-16 produced the highest number of polymorphism bands $47 \%$ and the lowest number of bands was produced by the OPA-05 primer $24 \%$. Dehghanzadeh and his colleagues presented the RAPD profiles of Iranian native chicken in five populations, with a total of 130 fragments amplified in which 86 bands showed polymorphism and the greatest number of polymorphic bands detected were 16 (Dehghanzadeh et al., 2009). The overall number of polymorphic loci, percentage of polymorphic loci and genetic diversity were $25,64.10 \%$ and 0.25 , respectively in Bangladeshi chicken and the average detected with the average number of bands obtained by individual primer ranging from 9 to 11 (Mollah et al., 2009).

\section{Genetic distance}

The Nei's mean distance value among population of Sakini was 0.194 \pm 0.016 . UPGMA cluster analysis, based on the genetic distance, shows that the population 
grouped according to the geographical regions, generating four distinct groups. Population was found significant to geographical regions. Nei's heterozygosity for all loci ranges from 0.022 to 0.692 . The Nei's heterozygosity mean for all loci of Rasuwa is $0.593 \pm 0.022$, Kavre $0.552 \pm 0.188$ and Rauthat $0.568 \pm 0.05$, respectively. The distance calculated range from 0.066 to 0.182 in Irani native chicken (Dehghanzadeh et al., 2009), whereas, in Bangladeshi chicken the values of pair wise comparison of genetic distance between populations ranged from 0.036 to 0.148 as presented by Mollah et al. (2009).

\section{Cluster analysis}

The cluster analysis based on UPGMA clustering with 59 loci generated by seven RAPD primers separates 20 Sakini birds of three different ecological zones into six major clusters in $88 \%$ similarity level (Figure1), whereas, Maeda et al. (1992) present three types of local chicken while studying protein polymorphisms in native and red jungle fowls in Nepal. Bootstrap of 1000 replication was done which suggest the highest recovery from resampling by RT4 bird of Rauthat and K17 bird of Rasuwa. The result shows six distinct types of Sakini chicken at $88 \%$ of the similarity level. Five regional chicken populations in the central part of Nepal were clustered into three groups. Among the five regions, two regions were from high hills $(2500 \mathrm{~m})$, two regions from mid-hills and one region from plane land (Terai). According to Dorji et al. (2012) there are 13 strains of native chickens in Bhutan. However, the FAO Domestic Animal Diversity Information System lists only 10 strains. 


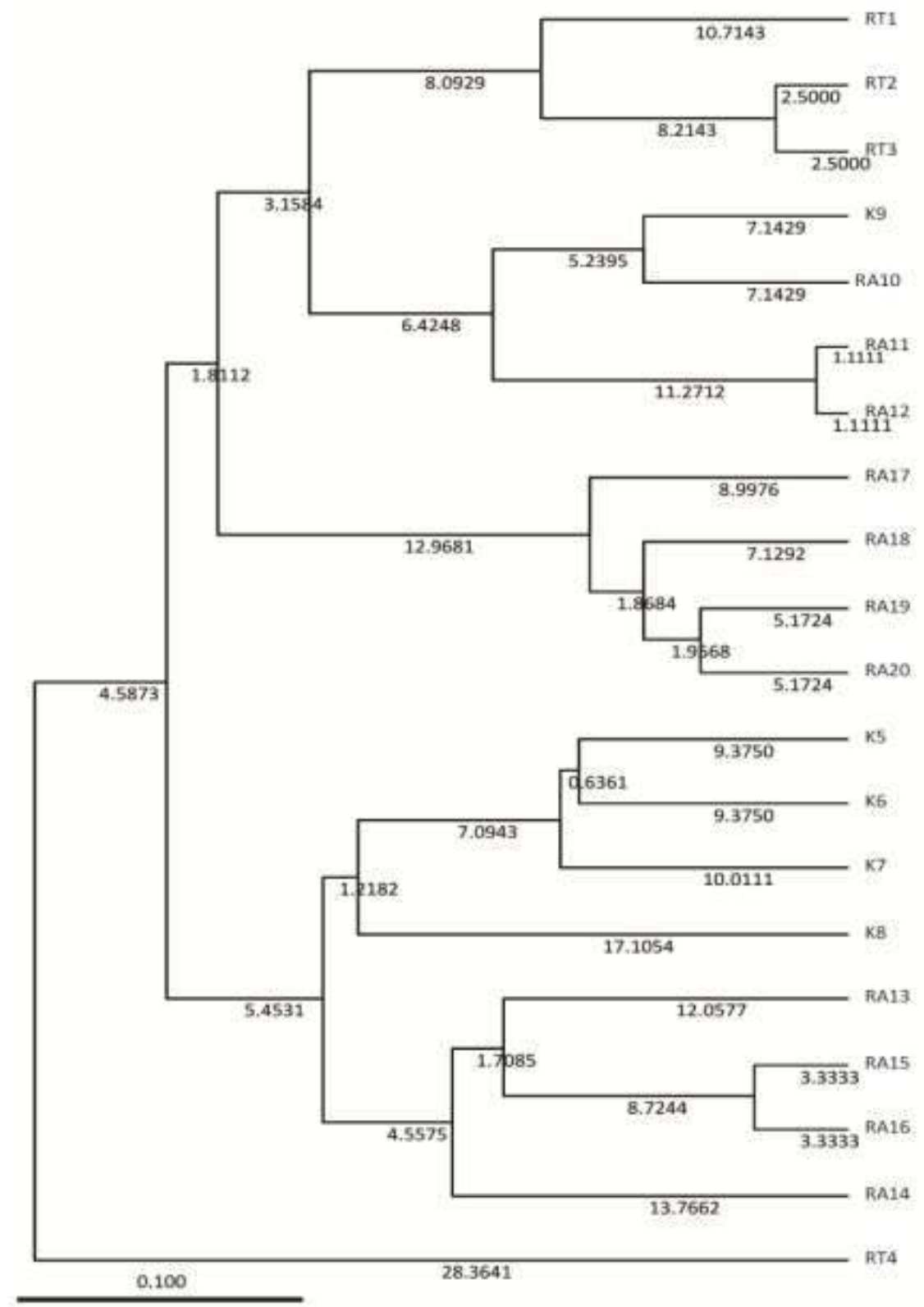

Figure 1. Dendrogram showing 20 Sakini individuals based on Nei's genetic distance using UPGMA method with Bootstrap of 1000 replication 
The efficacy of the RAPD markers in detecting the polymorphism among the Sakini chicken population from different locations of Nepal was revealed using this experiment. This helped to establish the genetic relationship among various Sakini breeds of Nepal. The seven primer of RAPD generated 59 different bands with an average of 8.4 bands per primer. The Nei's mean distance value among population of Sakini was $0.194 \pm 0.016$. UPGMA cluster based on the genetic distance shows that population grouped according to the geographical regions, generating six distinct groups and was found significant to geographical region. Upon principal coordinate analysis of 1 versus 2 shows three lines of Sakini chicken were distinctly different lines and there is wide dissimilarity between different three lines. Analysis of molecular variance within population was $75 \%$ and among the population variance of $25 \%$ and this result was found to be statically significant $(\mathrm{p}<0.01)$ indicates population differ significantly from each another. This result also shows that further study needs to be done to find out reason (s) for huge variation within the population.

\section{Principle component analysis}

The cluster pattern is well supported by the principle component analysis that also separates all three lines of Sakini chicken into six major groups. Upon PCO analysis variation in $\mathrm{X}$ axis was found $42.35 \%$, $\mathrm{Y}$ axis $23 \%$ and $\mathrm{Z}$ axis $13.25 \%$. These cluster 1 verse 2 showed that the three lines of Sakinichicken were distinctly different lines and there is wide dissimilarity between different three lines. Maeda (1988) presented the first three components were $46 \%, 34 \%$ and $18 \%$ in protein polymorphism of native chicken of Nepal and concluded five regional chicken population in central part of Nepal were clustered into three groups. Sample numbers RT1 (2.7), RT 3 (2.99), K 5 (-3.7), K6 (-3.35), RA15 (-3.14), and RA16 (3.79) created high variation in first principle component, sample numbers RT1 (1.93), K6 (-2.13), RA17 (2.67), RA18 (2.7), RA19 (3.78), RA20 (4.12) created highest variation in second principle component and sample numbers K5 (-2.5), K6 (-2.2), K7 (-1.6), RA13 (1.7), RA15 (2.2), and RA16 (2.5) created highest variation in third principle component.

\section{Analysis of molecular variance}

The Analysis of molecular variance (AMOVA) was performed from RAPD data considering three populations. Analysis of molecular variance (Table 2) shows that the most of variability within population ( $75 \%$ of variance) and among the population variance of $25 \%$. This result was found to be statically significant $(\mathrm{P}<0.01)$ indicates that population differ significantly from one another. These data were supported by a PhiPT $=0.355$, which measures the magnitude of genetic differentiation among population. The reason for low variance among the population due to Sakini is the principle breed of Nepal and it can be found in wide geographical regions. As well as the Sakini of all region is from the same family. But 
the variation within the present populations may be due to different genetic makeup, species adaption, natural selection, history of birds, migration, mutation, even more by genetic contamination by other exotic species.

Table 2. Analysis of molecular variance

\begin{tabular}{llllll}
\hline Source & Df & SS & MS & Est. Var. & $\%$ \\
\hline Among Pops & 2 & 53.514 & 26.757 & 2.978 & $25 \%$ \\
Within Pops & 17 & 153.686 & 9.040 & 9.040 & $75 \%$ \\
Total & 19 & 207.200 & & 12.018 & $100 \%$ \\
Stat & Value & P(rand $>$ =data) & & PhiPT max & Phi'PT \\
PhiPT & 0.248 & 0.010 & & 0.698 & 0.355 \\
\hline
\end{tabular}

\section{Molecular genetic diversity of population}

According to Nei (1973) heterozygosity for all loci ranges from 0.103 to 0.692 with mean $0.194 \pm 0.016$, similarly unbiased hetro-zygosity was $0.210 \pm 0.016$ (Table3). The Nei's heterozygosity mean for all loci of Rasuwa is $0.267 \pm 0.022$, Kavre $0.231 \pm 0.023$ and Rauthat $0.082 \pm 0.021$ respectively. Mean Shannon's information index was found to be 0.292 where number of alleles was $1.305 \pm 0.064$ with effective number of alleles $1.325 \pm 0.027$. Shannon's information index for was found to be 0.292 where number of alleles was $0.406 \pm 0.031,0.346 \pm 0.037,0.124 \pm 0.031$ with effective number of alleles $1.440 \pm 0.043,1.396 \pm 0.049,1.140 \pm 0.038$ of Rasuwa, Kavre and Rauthat respectively.

Table 3. Mean and standard error over loci for each population

\begin{tabular}{lccccccc}
\hline Pop & & $\mathrm{N}$ & $\mathrm{Na}$ & $\mathrm{Ne}$ & $\mathrm{I}$ & $\mathrm{He}$ & $\mathrm{uHe}$ \\
\hline Rautahat & Mean & 4.000 & 0.695 & 1.140 & 0.124 & 0.082 & 0.094 \\
& $\mathrm{SE}$ & 0.000 & 0.109 & 0.038 & 0.031 & 0.021 & 0.024 \\
Kavre & Mean & 5.000 & 1.475 & 1.396 & 0.346 & 0.231 & 0.257 \\
& $\mathrm{SE}$ & 0.000 & 0.101 & 0.049 & 0.037 & 0.026 & 0.029 \\
Rasuwa & Mean & 11.000 & 1.746 & 1.440 & 0.406 & 0.267 & 0.280 \\
& $\mathrm{SE}$ & 0.000 & 0.075 & 0.043 & 0.031 & 0.022 & 0.024 \\
Total & Mean & 6.667 & 1.305 & 1.325 & 0.292 & 0.194 & 0.210 \\
& $\mathrm{SE}$ & 0.233 & 0.064 & 0.027 & 0.021 & 0.015 & 0.016 \\
\hline
\end{tabular}

$\mathrm{Na}=$ No. of Different alleles; $\mathrm{Ne}=$ No. of effective alleles $=1 /\left(\mathrm{p}^{\wedge} 2+\mathrm{q}^{\wedge} 2\right) ; \mathrm{I}=$ Shannon's Information Index $=-1^{*}(\mathrm{p} * \operatorname{Ln}(\mathrm{p})+\mathrm{q} * \operatorname{Ln}(\mathrm{q}))$; He $=$ Expected Heterozygosity $=2 * \mathrm{p} * \mathrm{q} ; \mathrm{uHe}=$ Unbiased expected Heterozygosity $=(2 \mathrm{~N} /(2 \mathrm{~N}-1))$ $* \mathrm{He}$ 


\section{Percentage of polymorphic loci}

The average of $56.5 \%$ with stander devotions of $17.0 \%$ polymorphic loci was shown by the seven primers (Table4). The L3 Line (Rasuwa) showed $81.36 \%$, L2 line (Kavre) showed $64.41 \%$ and L1 line (Rauthat) showed $23.73 \%$ of Polymorphic loci.

Table 4. Percentage of polymorphic loci of three lines of seven different RAPD primers

\begin{tabular}{ccccc}
\hline Population & Rautahat & Kavre & Rasuwa & Mean \\
\hline$\% \mathrm{P}$ & $23.73 \%$ & $64.41 \%$ & $81.36 \%$ & $56.5 \pm 17.10 \%$ \\
\hline
\end{tabular}

\section{CONCLUSION}

Based on the results, it can be concluded that there are six sub-lines and may have sub-sub lines of Sakini chicken within the geographical region. RAPD effectiveness in detecting polymorphism is high and this technique is simple and straightforward in a preliminary assessment of within and between population genetic diversity in local poultry breed.

\section{ACKNOWLEDGEMENTS}

The authors are very thankful to the farmers who helped by providing local chicken as well as Research Stations and Government Farms for providing chicken for research purposes. Animal Breeding Division and Swine and Avian Research Program, Khumaltar and their staffs also deserve high acknowledgment for their cooperation and support during the entire research period. We are very thankful to the Nepal Agricultural Research Council for providing the fund for the research.

\section{REFERENCES}

Cheng, H.H., Levin I., Vallejo, R.L., Khatib H., Dodgson J.B., Crittenden L.B. and Hillel J. (1995). Development of a genetic map of the chicken with markers of high utility. Poultry Science, 74(11):1855-1874.

Dehghanzadeh, H., Mirhoseini, S.Z., Romanov, M.N. and Ghorbani, A. (2009). Evaluation of genetic variability and distances among five Iranian native chicken populations using RAPD markers. Pakistan Journal of Biological Sciences, 12(11):866-871.

Dorji, N., Duangjinda, M. and Phasuk, Y. (2012). Genetic characterization of Bhutanese native chickens based on an analysis of Red Jungle fowl (Gallus gallusgallus and Gallus gallusspadecieus), domestic Southeast Asian and commercial chicken lines (Gallus gallusdomesticus). Genetics and Molecular Biology, 35(3):603-609. 
Gilbert, D.A., Lehman, N., O'Brien, S.J. and Wayne, R.K. (1990). Genetic fingerprinting reflects population differentiation in the California Channel Island fox. Nature, 344(6268):764-767.

Levin, I., Crittenden, L. B. and Dodgson, J. B. (1994). Mapping DNA polymorphisms using PCR primers derived from the sequence of an avian CR1 element. The Journal of Heredity, 85(2):73-78.

Livestock Statistics. (2015). Department of Livestock Services. Ministry of Livestock Development. Government of Nepal.

Lynch, M. (1990). The similarity index and DNA fingerprinting. Molecular Biology and Evolution, 7(5):478-484.

Maeda, Y., Yamamoto, Y., Nishida, T., Hashiguchi, T., Okada, I. and Rajbhandary, H.B. (1992). Protein polymorphisms in native and Red Jungle fowls in Nepal. Asian-Australasian Journal of Animal Science, 5(4):747-752.

Mollah, M.B.R., Islam, F.B., Islam, M.S., Ali, M.A. and Alam, M.S. (2009). Analysis of genetic diversity in Bangladeshi chicken using RAPD markers. Biotechnology, 8(4):462-467.

Nei, M. (1973). Analysis of gene diversity in subdivided populations. Proceedings of the National Academy of Sciences of the United States of America, 70(12):3321-3323.

Neopane, S.P. and Gorkhali, N.A. (2008). Indigenous chicken of Nepal. Nepal Agricultural Research Council (NARC), Khumaltar, Lalitpur. Pp. 1-10.

Salem, H.H., Ali, B.A., Huang, T. and Qin, D. (2005). Use of Randomly Amplified Polymorphic DNA (RAPD) Markers in Poultry Research. International Journal of Poultry Science, 4(10):804-811.

Sapkota, S., Kolachhapati, M.R., Devkota, N.R., Gorkhali, N.A. and Bhattarai, N. (2017). Evaluation of egg laying and egg quality parameters of local chicken Sakini (Gallus gallus domesticus) of Nepal. Journal of Agriculture and Forestry University: 1:181-188.

Smith, E.J., Jones, C.P., Barlett, J. and Nestor, K.E. (1996). Use of randomly amplified polymorphic DNA markers for the genetic analysis of relatedness and diversity in chickens and turkeys. Poultry Science, 75(5):579-584.

Welsh, J. and McClelland, M. (1990). Fingerprinting genomes using PCR with arbitrary primers. Nucleic Acids Research, 18(24):7213-7218.

Williams, J.G., Kubelik, A.R., Livak, K.J., Rafalski, J.A. and Tingey, S.V. (1990). DNA polymorphisms amplified by arbitrary primers are useful as genetic markers. Nucleic Acids Research, 18(22):6531-6535.

Wilson, R.T. (2017). Domestic livestock in Nepal: Production systems, genetic resources, research and the way forward. International Journal of Agricultural Management, 6(2): 50-61. 